\title{
Frequency Agile Triple Band Microstrip Antenna for WLAN/WiMAX Application
}

\author{
Sudarshan Joshi, A. K. Gautam, and Rajesh Upadhyay
}

\begin{abstract}
A frequency agile triple band microstrip antenna using defected ground structure for WLAN/WiMAX application is presented, in which frequency agility is electronically achieved by changing the bias voltage of varactor diode. A defected ground structure rectangular patch with dual inverted L-shaped fed with a cross shaped strip line is used to achieve multiple bands. Simulated results are validated by the experimental results and show a good agreement between simulated and experimental results. The proposed antenna has small size and operates 2-2.15 GHz, 2.75-3.5204 and 5.4-5.9 GHz. The lower and upper band remains almost constant while resonance frequency of the middle band is changing with the bias voltage of varactor diode and frequency agility of 768.4 $\mathrm{MHz}$ is achieved. Thus the proposed antenna is suitable to be used for WLAN and WiMAX applications.
\end{abstract}

Index Terms-Multiband antenna, defected ground structure, frequency agile microstrip antenna, triple band, wimax, wlan.

\section{INTRODUCTION}

Multiband antennas perform exceptionally well in aggregating various communication standards in a single platform. Communication standards like wireless local area network (WLAN) and worldwide interoperability of microwave access (WiMAX) need antennas which possess compact size and multiband operations. Other structures have also been proposed by the researchers for reduction of size, bandwidth enhancement and resonance-mode increment [1]-[3]. Further, a solid ground plane is replaced by a recently invented defected ground structure [4]-[6]. The advantage of defected ground plane is reduction of size and excitation of additional resonance bands. $\mathrm{L}$ shaped strips are loaded to modify the radiating element and feeding with a cross shaped stripline. The reduction of size can prevent large surface wave loss so it can be used as an array element also [7]. However, the proposed antenna has various inherent advantages such as low profile, light weight, easy fabrication, and suitability of mass production. It has also been found suitable in integrating various communication standards. However, on reducing the size of an antenna makes the radiation efficiency low and it narrowed the bandwidth. Active microstrip antennas have become one of the mainstay components of modern communication system due to its frequency agility, simple structure and an efficient radiating

Manuscript received December 24, 2013; revised February 19, 2014.

Sudarshan Joshi is with the Amrapali Institute of technology and Sciences, Haldwani, India (e-mail: sudarshanjoshi2007@yahoo.com).

A. K. Gautam, was with Electronics and Communication Department, Govind Ballabh Pant Engineering College, Pauri, India (e-mail: gautam1575@yahoo.co.in).

Rajesh Upadhyay is with the Government Polytechnic, SIDCUL, Haridwar, India . element. Their relative compact structure, low cost and fast installation makes them an obvious choice for raises the mobility of the communication system [8]-[11]. Many different types of active antenna structure has been investigated and used in various communication applications.

In this paper, a frequency agile triple band microstrip antenna using defected ground structure for WLAN/WiMAX application is proposed. The radiating patch is loaded with protrudent strip and varactor diode and fed with a cross shaped strip line as shown in Fig. 1. To excite the triple resonant band, the ground is cut out by shaped slots as a result the defected ground structure is formed. Further, a varactor is loaded with the above structure to achieve frequency agility in the middle band while two other bands remain unaffected. As the bias voltage of the varactor diode changes, the capacitance introduced at the radiating edge is changed and resulting in change in the resonant frequency of the middle resonant band [12]. Thus, the resonance of the middle band of the micro strip antenna is electronically controlled by the reverse bias of varactor diode. Simulated results for the active microstrip antenna has been obtained and validated with the measured results, which shows a good agreement with the measured results. The proposed antenna can operate at two multiband wireless communication system such as the wireless local area network (WLAN) 2.4/5.2/5.8 GHz and the world wide interoperability for microwave access (WiMAX) 3.5/5.5 GHz. The detail of entire investigations is given in the following sections.

\section{ANTENNA DESIGN AND SIMULATION}

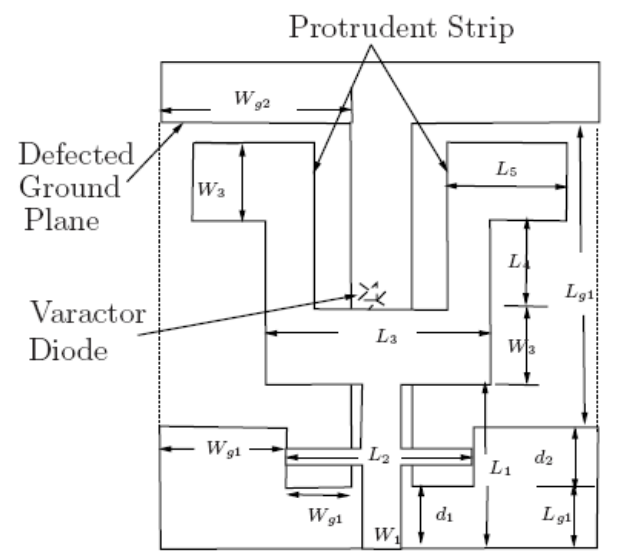

Fig. 1. Schematic configuration of frequency agile triple band microstrip antenna using defected ground structure.

The geometry of a rectangular patch antenna loaded with two inverted L shaped strips, a cross shaped strip and defected ground plane is shown in Fig. 1. The conductor plane is etched on the upper side while the ground plane is on lower side of the PCB. The dielectric constant is 4.4 and substrate thickness is $1.6 \mathrm{~mm}$. The radiator is a rectangular 
patch of dimension $10 \times 6 \mathrm{~mm}$ loaded with two inverted $\mathrm{L}$ shaped strip from the patchs upper two sides. The dimensions of the $\mathrm{L}$ shaped strips having both horizontal and vertical strips are $5 \times 5 \mathrm{~mm}$ and $5 \times 2 \mathrm{~mm}$, respectively. A cross-shaped stripline is used for feeding which comprises both the vertical and horizontal strips with dimensions of $9 \times 2 \mathrm{~mm}$ and $8 \times 1 \mathrm{~mm}$ and a distance of $5 \mathrm{~mm}$ between the horizontal strip and the feed point. The overall size of the ground plane is $20 \times 30$, and each of the embedded slots has a vertical section of $4 \times 2 \mathrm{~mm}$ as well as a horizontal section of $18 \times 8 \mathrm{~mm}$. Meanwhile, the slot is etched with a distance of $4 \mathrm{~mm}$ from the bottom of the ground and its vertical section has a distance of $6 \mathrm{~mm}$ from the ground side edge. The varicap diode is loaded at the upper most edge of the rectangular radiator patch at point $(a, b)$. The varactor diode when reverse biased is shown in Fig. 1, in which $L p$ and $C p$ represent parasitic inductance and capacitance associated with the mounting and packaging of the device. Rs is the spreading resistance associated with the finite thickness of the epitaxial layer as well as the ohmic contact of the diode and $C T$ is the bias dependent capacitance which is used to obtain the tunable resonance frequency in microstrip antenna. The following relation can be used for calculating the range of transition capacitance that may be required for achieving a tunable frequency range [12].

$$
C_{T}=C_{0}\left(1+\left|\frac{V_{r}}{V_{T}}\right|\right)^{-n}
$$

where $C_{0}$ is the value of $\mathrm{CT}$ at zero bias voltage; $V r$ the value of DC reverse bias; VT the threshold voltage; $n=1 /(m+2)$; and $\mathrm{m}$ is a constant number depending upon the type of $\mathrm{p}-\mathrm{n}$ junction doping. The Table I (tab) shows, the typical design parameters for varactor diode.

The investigation has been carried out using the electromagnetic simulator IE3D (Zeland software, USA) which is generally considered as an efficient and reliable tool for the simulation of various antenna configuration. Firstly the effect of loading microstrips of different dimensions with defected ground plane is studied and then varactor loaded structure is studied.

TABLE I: DESIGN PARAMETERS FOR VARACTOR DIODE USED WITH ANTENNA

\begin{tabular}{|l|l|}
\hline \multicolumn{1}{|c|}{ Design Parameter } & \multicolumn{1}{c|}{ Value } \\
\hline Mount and packaging inductance, $\mathrm{Lp}$ & $0.4 \mathrm{nH}$ \\
\hline Mount and packaging Capacitance, $\mathrm{Cp}$ & $0.15 \mathrm{pF}$ \\
\hline Spreading resistance, Rs & $2.27 \Omega$ \\
\hline Threshold voltage for varactor diode, $V_{T}$ & $0.70 \mathrm{~V}$ \\
\hline Type of doping profile & $m=-0.5$ \\
\hline Hyper abrupt junction & $n=2$ \\
\hline Transition capacitance of varactor, $C_{T}$ & $(2.4-0.4) \mathrm{pF}$ \\
\hline Reverse bias voltage, $V_{r}$ & $0--30 \mathrm{~V}$ \\
\hline
\end{tabular}

\section{RESULTS AND DISCUSSION}

Various antenna structures were successfully implemented. The simulated results are validated with measured results and show a good agreement. The comparative study of different antenna structures with or without inverted L shaped strips, cross shaped strips and defected ground plane are carried out.
It is observed that the best results were obtained for $\mathrm{Wg} 1=$ $2 \mathrm{~mm}, \mathrm{Wg} 2=8 \mathrm{~mm}, 12=8 \mathrm{~mm}$, and $15=5 \mathrm{~mm}$. Fig. 2 shows, the simulated and measured return loss for various frequency with above dimensions. From the figure, three resonant bands are observed at $2.1 \mathrm{GHz}, 3.6 \mathrm{GHz}$ and $5.2 \mathrm{GHz}$ frequencies. It is found that the instantaneous bandwidths for three bands are about $190 \mathrm{MHz}(2.00-2.19 \mathrm{GHz}), 310 \mathrm{MHz}$ (3.41-3.72 GHz) and $690 \mathrm{MHz}(4.90-5.59 \mathrm{GHz})$, respectively. Further, it is also observed that loading of two inverted $\mathrm{L}$ shaped strips not only improves the impedance matching of the first and the third band but it can also excite an additional resonance at the second band. It is evidently clear from the Fig. 2 that the above results show good results for designing desired triple- frequency band antenna but still there is requirement to work on the instantaneous bandwidth of the these bands.

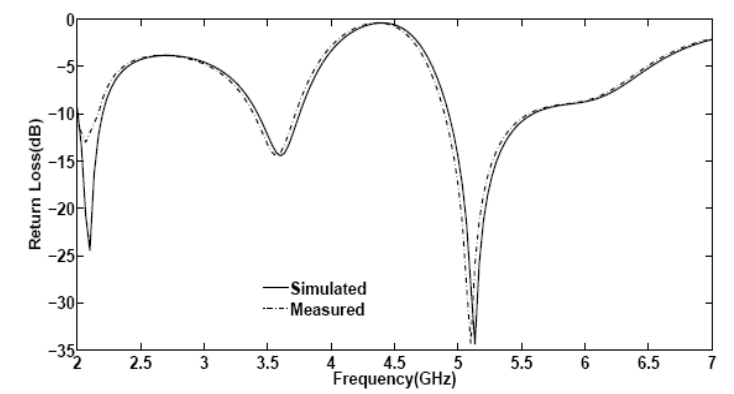

Fig. 2. Variation of the simulated and measured return losses for various frequency with $\mathrm{Wg} 1=2 \mathrm{~mm}, \mathrm{Wg} 2=8 \mathrm{~mm}, 12=8 \mathrm{~mm}, 15=5 \mathrm{~mm}$.

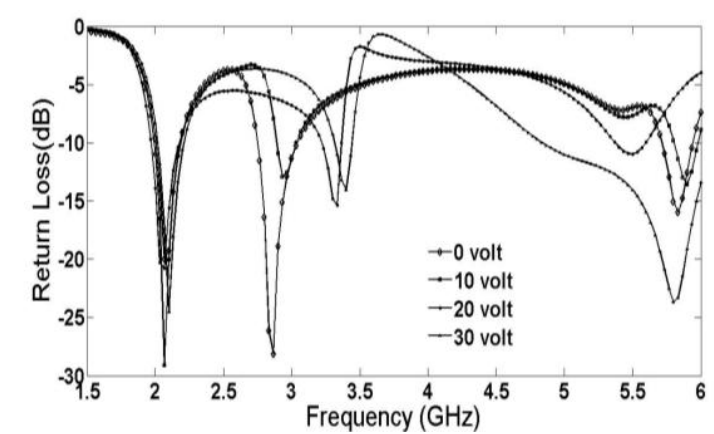

Fig. 3. Variation of return loss for different bias voltages of varactor diode.

Thus, it is decided to integrate a varactor diode with above antenna and it is found that the resonance of middle band can be controlled by varying the reverse bias voltage of varactor diode without affecting other bands. Variation of resonance frequency for varactor loaded active microstrip antenna is shown in Fig. 3. The range of frequency achievable for operation is $730 \mathrm{MHz}$ for the second resonating mode. Since, the microstrip antenna is a parallel tuned circuit and when varactor is loaded with the antenna, the equivalent circuit of the varactor will be parallel with microstrip antenna. The fringing capacitance introduced at the radiating edge is changed with the change in the bias voltage, resulting in a change in the electrical length of the patch and thus its resonant frequency. So, the resonance of the microstrip antenna is electronically controlled by the reverse bias of varactor diode. It is evidently clear that the frequency agile active microstrip antenna can be operate with varying tuning capability at microwave range by controlling the bias voltage of suitable device integrated with the patch. Fig. 4 shows the directivity of the antenna with and without loading of the varactor diode. It is observed that the loading of varactor diode improved the directivity of the active antenna. The 
radiation efficiency of the antenna with and without loading of the varactor diode is shown in Fig. 5 in which the radiation efficiency is decreases with loading of the varactor. Radiation pattern of the antenna is shown in Fig. 6. Radiation pattern of the antenna is invariant with the bias voltage. Therefore, it is expected that the antenna performance will remain satisfactory for the entire tuning range.

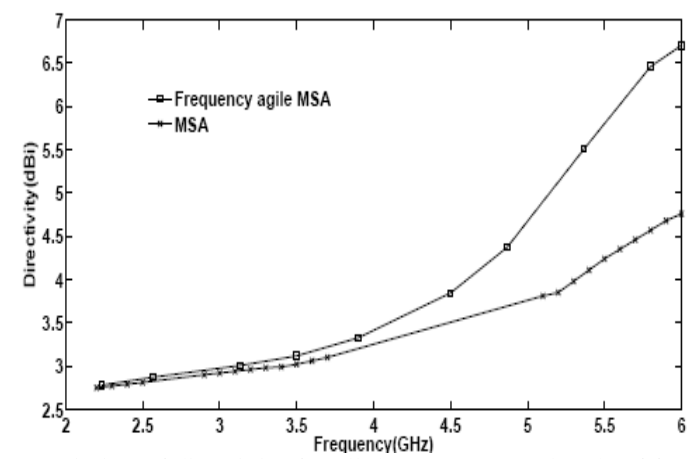

Fig. 4. Variation of directivity for all three resonance bands of frequency agile active microstrip antenna using defected ground structure.

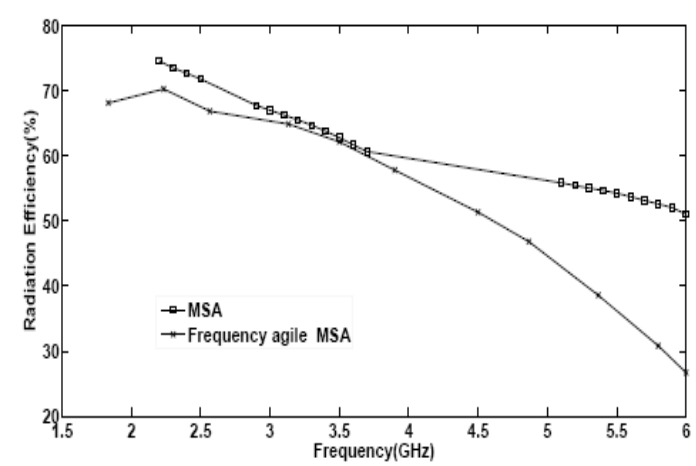

Fig. 5. Variation of radiation efficiency for all three resonance bands of frequency agile active microstrip antenna using defected ground structure.

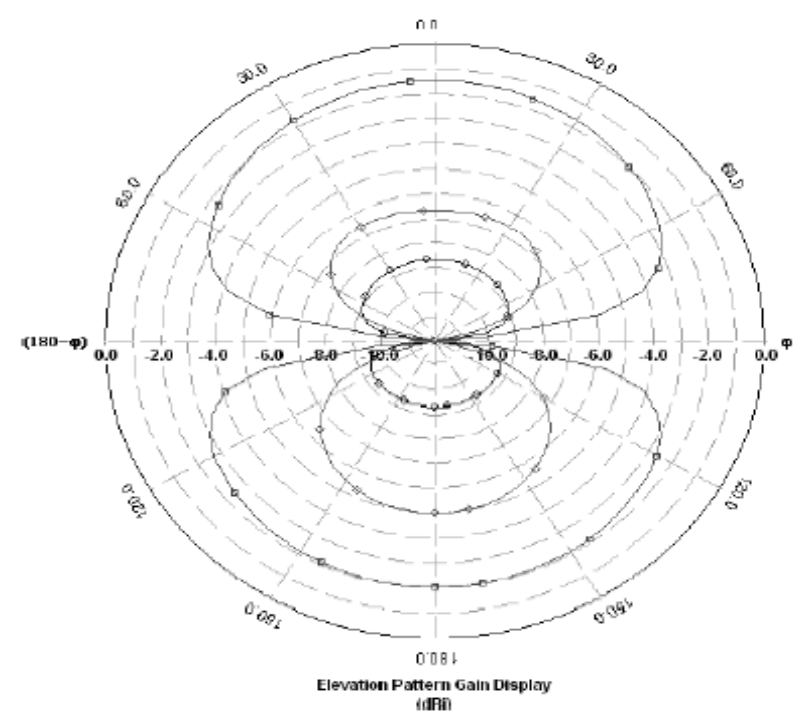

Fig. 6. Radiation pattern of frequency agile active microstrip antenna using defected ground structure.

\section{CONCLUSION}

A frequency agile triple band microstrip antenna using defected ground structure for WLAN/WiMAX application is successfully implemented. By loading an active device we can enhance the frequency agility. The frequency agile active microstrip antenna can be operated with varying tuning capabilities at microwave range by controlling the bias voltage of varactor diode integrated with patch. The proposed antenna has small size and operates $2-2.15 \mathrm{GHz}$, 2.75-3.5204 and 5.4-5.9 GHz. The lower and upper band remains almost constant while resonance frequency of the middle band is changing with the bias voltage of varactor diode and frequency agility of $768.4 \mathrm{MHz}$ is achieved. Thus the proposed antenna is suitable to be used for WLAN and WiMAX applications. The directivity of the frequency agile active microstrip antenna using defected ground structure is improved.

\section{REFERENCES}

[1] K. Seol, J. Jung, and J. Choi, "Multi-band monopole antenna with inverted u-shaped parasitic plane," Electron Letters, vol. 42, no. 15, pp. 844-845, 2006.

[2] C. M. Wu, C. N. Chiu, and C. K. Hsu, "A new nonuniform meandered and fork-type grounded antenna for triple-band wlan applications," IEEE Transaction on Antennas wireless Propagation letters, vol. 5, no. $1,2006$.

[3] H. C. Go and Y. W. Jang, "Multi-band modified fork-shaped microstrip monopole antenna with ground plane including dualtriangle portion," Electron Letters, vol. 40, no. 10, pp. 575-577, 2004.

[4] J. P. Thakur and J. S. Park, "An advance design approach for circular polarization of the microstrip antenna with unbalance dgs feedlines," IEEE Transaction on Antennas Wireless Propagation Letters, vol. 5, no. $1,2006$.

[5] M. A. Antoniades and G. V. Eleftheriades, "A compact multiband monopole antenna with a defected ground plane," IEEE Transaction on Antennas Wireless Propagation Letters, vol. 7, pp. 652-655, 2008.

[6] K. H. Chiang and K. W. Tam, "Microstrip monopole mntenna with enhanced bandwidth using defected ground structure," IEEE Transaction on Antennas Wireless Propagation Letters, vol. 7, pp. 532-535, 2008.

[7] C. M. W. W. C. Liu, and Y. Dai, "Design of triple-frequency microstrip-fed monopole antenna using defected ground structure," IEEE Transactions on Antennas and Propagation, no. 7, 2011.

[8] A. K. Gautam and B. R. Vishvakarma, "Frequency agile microstrip antenna symmetrically loaded with tunnel diodes," Microwave and optical technology letters (USA), vol. 48, no. 9, pp. 1807-1810., 2006.

[9] A. K. Gautam and B. R. Vishvakarma, "Frequency agile active microstrip antenna," Microwave and optical technology letters (USA), vol. 49, no. 2, pp. 431-434, 2007.

[10] R. B. Waterhouse and N. B. Shuley, "Frequency agile microstrip rectangular patches using varactor diode," IEEE Antenna and propagation Society International Symposium Digest, held in conjunction with URSI Radio Science Meeting and Nuclear EMP Meeting, vol. 4, pp. 2188-2191, 18-25th July 1992.

[11] P. Bhartia and I. J. Bahl, "Frequency agile microstrip antennas," Microwave Journal, vol. 25, pp. 67-70, October 1982.

[12] R. Boylestad and L. Nashelsky, Electronics Devices and Circuit Theory, Prentice-Hall of India, 1989.

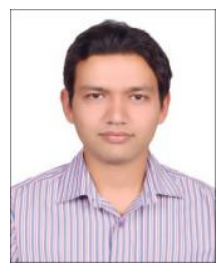

Sudarshan Joshi was born in Jodhpur, Rajasthan, India in 1984. He received his B. Tech. degree in electronics and communication engineering from Uttarpradesh Technical University, Uttarpradesh, India in 2008. M. Tech. degree in digital signal processing from Uttrakhand Technical University, Uttarakhand, India in 2012.

From 2008 to 2010, he was a lecturer in Department of Electronics and Communication Engineering in Amrapali Institute of Technology and Sciences, Uttarakhand, India. He is currently working as assistant professor in Department of Electronics and Communication Engineering in amrapali institute of technology and sciences, Uttrakhand, India. His main research interests are printed antenna and application of optimization technique in antenna design.

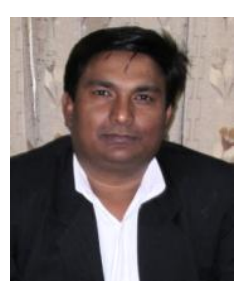

A. K. Gautam was born in Noida, India, in 1975. He received his B.E. degree in electronics \& communication engineering from Kumaon Engineering College, Almora, India and He received his Ph.D. degree in electronic engineering from Indian Institute of Technology, Banaras Hindu University, Varanasi, India, in 1999 and 2007, respectively. He joined the Department of Electronics \& Communication Engineering, G B Pant Engineering College, Pauri Garhwal, India, in 2000, and he has been an 
associate professor there since 2009

Dr. Gautam is an active member of Board of study, Academic council and many other academic committees of GBPEC, Pauri. Dr. Gautam is also member of BOS of HNBG Central University and Uttarakhand Technical University, Dehradun. Dr. Gautam is nominated as Nodal Officer, TSP and SCSP Grants by Government of Uttarakhand and executed several project under these grants. Dr Gautam has supervised $10 \mathrm{M}$. Tech. Thesis and supervising $06 \mathrm{PhD}$ theses in the area of Microstrip antenna.

Dr. Gautam is the author/coauthor of more than 40 research papers published in the refereed international journals and conferences. He is the author of the 13 books in the field of Electronics Engineering in the field of Digital Electronics, Antenna and Microwave Engineering. He is a member of IEEE (USA) and many other technical societies. His main research interest are in design and Modeling of Microstrip Antenna, DGS microstrip antennas, Ultra wide bandwidth antennas, and reconfigure able antennas, reconfiguration antenna array, circular polarized antenna, etc.

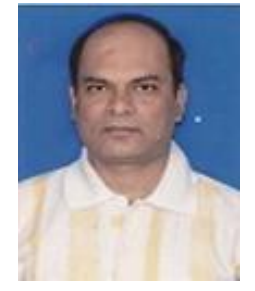

Rajesh Upadhyay was a technocrat \& management professional, presently working as Principal at Government Polytechnic, SIDCUL, Haridwar- Uttarakhand did his Master of Engineering (ME) in digital systems in 1997 from Motilal Nehru National Institute of Technology, Allahabad. Dr. Rajesh Upadhyay did his master of business administration (MBA) in HRM in 2005 from Indira Gandhi National Open University and Doctor of Philosophy (Ph.D.) in management on "The Impact Analysis of usage of Information and Communication Technology in an educational environment : A case study of Uttarakhand Government technical Education Institutions" from Singhania University in 2012. Dr. Rajesh Upadhyay is having 10 years of teaching experience at undergraduate level of engineering in Government engineering college in Uttarakhand and 6 years of administrative experience as Principal in Technical Education Department of Uttarakhand. His area of interest is digital signal processing, data communication including power and radiation aspects of an Antenna. 